\title{
Presentation and outcomes of early and late onset neonatal sepsis in a Nigerian Hospital
}

\author{
Ezra Ogundare ${ }^{1}$, Akinyemi Akintayo ${ }^{2}$, Theophilus Aladekomo ${ }^{3}$, Lateef Adeyemi ${ }^{4}$, \\ Tinuade Ogunlesi ${ }^{5}$, Oyeku Oyelami ${ }^{6}$
}

1. Ekiti State University, Paediatrics; Ekiti State University Teaching Hospital, Paediatrics.

2. Ekiti State University, Obstetrics and Gynaecology; Ekiti State University Teaching Hospital, Obstetrics and Gynaecology.

3. Obafemi Awolowo University College of Health Sciences, Paediatrics and Child Health.

4. Obafemi Awolowo University Teaching Hospitals Complex, Medical Microbiology.

5. Olabisi Onabanjo University, Paediatrics.

6. Obafemi Awolowo University, College of Health Sciences, Department of Paediatrics and Child Health.

\begin{abstract}
Background: Neonatal Sepsis remains a major cause of morbidity and mortality in neonates despite great advances in antimicrobial therapy and life support measures.

Objectives: To compare the aetiology, risk factors, presentation and outcomes of care between early onset neonatal sepsis (EOS) and late onset neonatal sepsis (LOS).

Methods: Bacterial isolates were identified using blood cultures and antibiotic susceptibility testing was done using disc diffusion method. The risk factors, clinical presentation, laboratory findings and neonatal outcomes of the babies with EOS were compared with LOS. Statistical significance was set at $\mathrm{P}<0.05$.

Results: Neonatal Sepsis was responsible for $16 \%$ of Special Care Baby Unit (SCBU) admissions. Of the 72 babies with sepsis, $56(77.8 \%)$ had EOS as against $16(22.2 \%)$ who had late-onset sepsis. Low birth weight $(\mathrm{p}=0.01)$ and perinatal asphyxia $(\mathrm{p}=0.01)$ were significantly associated with EOS while for LOS, delivery outside the health facility $(\mathrm{p}=0.01)$ was the only significant risk factor. Respiratory distress was more significantly observed in EOS $(p=0.01)$. Neonatal deaths occurred in $32 \%$ of babies with EOS while all babies with culture positive LOS survived.

Conclusion: Early onset neonatal sepsis is associated with high likelihood of neonatal mortality. Unsupervised delivery, birth asphyxia and low birth weight are risk factors associated with neonatal sepsis. Efforts to ensure supervised hospital delivery and improvement in neonatal resuscitation may reduce the incidence of neonatal sepsis and its attendant complications.
\end{abstract}

Keywords: Onset neonatal , Nigerian Hospital.

DOI: https://dx.doi.org/10.4314/ahs.v19i3.12

Cite as: Ogundare E, Akintayo A, Aladekomo T, Adeyemi L, Ogunlesi T, Oyelami O. Presentation and outcomes of early and late onset neonatal sepsis in a Nigerian Hospital. Afri Health Sci. 2019;19(3): 2390-2399. bttps:/ / dx.doi.org/ 10.4314/ahs.v19i3.12

\section{Introduction}

Neonatal sepsis is a clinical syndrome caused by systemic bacterial infection documented by a positive blood culture in the first four weeks of life. ${ }^{1,2}$ Neonatal Sepsis remains a major cause of morbidity and mortality in neonates despite great advances in antimicrobial therapy, life
Corresponding author:
Ezra Ogundare,
Ekiti State University,
Paediatrics; Ekiti State
University Teaching Hospital, Paediatrics.
Email: tundeyogundare@yahoo.com

support measures and the early detection of risk factors. ${ }^{1}$ Neonatal sepsis is estimated to cause almost one million deaths and accounts for more than $25 \%$ of neonatal deaths worldwide. ${ }^{3}$

Neonatal Sepsis can be classified as early-onset neonatal sepsis and late-onset neonatal sepsis based on the age of onset. Early-onset sepsis (EOS) is defined as onset of features of sepsis within $72 \mathrm{hrs}$ of life while Late-onset sepsis (LOS) is defined as onset of features of sepsis after $72 \mathrm{hrs}$ of life. ${ }^{1,4}$ EOS is usually caused by organisms acquired from the mother's genital tract or the organism prevalent in the designated place of delivery within the hospital. ${ }^{5,6}$ Most babies with EOS present with respiratory distress and it is associated with substantial morbidity

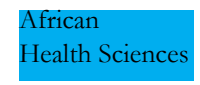

(C) 2019 Ogundare et al. Licensee African Health Sciences. This is an Open Access article distributed under the terms of the Creative commons Attribution License (https://creativecommons.org/licenses/BY/4.0), which permits unrestricted use, distribution, and reproduction in any medium, provided the original work is properly cited.

African Health Sciences Vol 19 Issue 3, September, 2019 
and mortality. ${ }^{7}$ LOS usually is due to organisms acquired from the environment as well as from the care-givers. ${ }^{6}$

The incidence, risk factors, pattern, antimicrobial sensitivities and mortality differ between the developed and developing countries. ${ }^{8}$ While group B Streptococcus is the leading cause of EOS in the developed countries, studies in developing countries have shown Klebsiella spp, Staphylococcus aureus and Escherichia coli as the leading causes. ${ }^{10} \mathrm{Co}-$ agulase negative Staphylococcus aureus is the leading cause of LOS in the developed countries while Staphyloccus aureus remains the leading cause of LOS in developing countries. $^{1}$

Diagnosis of neonatal sepsis requires a high index of suspicion as its symptoms and signs are non-specific.

The diagnosis of neonatal sepsis is confirmed by positive blood culture report however, the culture or incubation time may be up to $48-72$ hours; this is a major limitation to patient management.

This study was conducted to compare the aetiology, related factors, antibiotic susceptibility and outcomes of care between EOS and LOS in a sub-urban tertiary Hospital in South-West Nigeria. This information will serve as an evidence-based template for care of babies presenting with neonatal sepsis in this environment.

\section{Materials and methods}

This cross-sectional study was conducted at the Special Care Baby Unit (SCBU) of the Wesley Guild Hospital (WGH), Ilesa in 2009. This is a tertiary hospital and a unit of the Obafemi Awolowo University Teaching Hospitals Complex (OAUTHC), Ile-Ife. Ilesa, the largest town in Ijesaland, is situated on latitude $7^{\circ} 35^{\prime} \mathrm{N}$ and longitude $4^{\circ}$ 51 ' E, about 200 kilometers North-East of Lagos. The hospital serves as a multi-specialty referral centre for the communities of the Osun, Ondo and Ekiti States of South-Western Nigeria.

The study was part of a hospital-based prospective study carried out to determine the pattern of bacterial isolates and antibiotic sensitivity among neonates admitted into the SCBU of the hospital. ${ }^{11}$

All consecutive babies aged 0-28 days admitted to the SCBU of the WGH with presumed or probable sepsis were recruited. Septicaemia was presumed when a newborn baby has specific risk factors for sepsis like prematurity, delivery outside the hospital, prolonged labour, prolonged rupture of membranes, peri-partum pyrexia and chorioamnionitis without clinical manifestation.
Sepsis was probable in the presence of clinical features adjudged to be suggestive of sepsis, particularly fever or hypothermia, respiratory distress, jaundice, poor feeding, lethargy, poor cry and unexplained poor perfusion.

Babies were stratified into EOS if they presented within 72 hours of birth and LOS if they presented between 73 hrs and 28days. ${ }^{1}$

Babies with features suggestive of congenital heart diseases and metabolic disorders such as hypothyroidism were excluded from the study as well as neonates without risk factors or features suggestive of septicaemia.

Information about the age at admission, weight at admission, sex, estimated gestational age (EGA) at delivery, place of birth and details of perinatal events like duration of labour, interval between rupture of fetal membranes and the delivery of baby, occurrence of pyrexia during labour, mode of delivery and primary diagnosis on admission, were obtained with a use of a pre-tested study proforma.

Babies delivered at the WGH were designated inborn babies while babies delivered outside WGH but who were subsequently referred to WGH were designated out-born babies.

Blood culture samples, about $2 \mathrm{mls}$ of blood were collected from peripheral veins, under aseptic conditions, into the nutrient and thioglycolate broths prior the commencement of antibiotic therapy. The blood culture broths were immediately sent to the laboratory, where they were incubated at $37^{\circ} \mathrm{C}$ for 7 days. Three subcultures were made; at 24 hours, 72 hours and on the $7^{\text {th }}$ day on macconkey and Blood agar media. Organisms isolated were identified by conventional methods as described by Akonai et al. ${ }^{12}$

The aerobic isolates were studied in detail using Gram staining, colony characteristics and other biochemical features. Antibiotic susceptibility was determined by the disc-diffusion method using impregnated antibiotic discs. ${ }^{13}$ After blood sample collection, the neonates were commenced on empirical antibiotics Ampicillin and Gentamicin based on the recommendations of Owa et $\mathrm{al}^{14}$ from a study done about twenty years prior to this study in the same centre.

Prolonged rupture of membranes was defined as rupture of fetal membranes greater than 24 hours. Prolonged labour was defined as one lasting greater than 12 hours in the active phase of labour or 24 hours in totality. The 
socio-economic stratification was done using the method recommended by Olusanya and Okpere. ${ }^{15}$

The course of the illness including complications was recorded and compared between those with EOS versus LOS. The outcome of hospitalization was recorded as either discharge in good condition, discharge against medical advice or death.

Ethical approval was obtained from the Research and Ethical Clearance Committee of the Obafemi Awolowo University Teaching Hospitals Complex.

Written informed consent was obtained from either the parent(s) or the care-giver(s).

Maternal data obtained included age, parity, occupation, educational status, history of antenatal care, details of labour and delivery including the place of delivery, history of peri-partum fever, preterm labour, pre-labour rupture of foetal membranes, prolonged rupture of membranes, duration of labour as well as mode of delivery.

Data analysis was done using the SPSS for Windows software version $15 .{ }^{16}$ Means, standard deviations (SD), proportions and percentages were determined as applicable. The means and standard deviations (SD) were calculated for continuous variables while ratios and proportions were calculated for discrete variables. Univariate and multivariate regression analysis were done to determine association of risk factor and clinical presentation with early and late onset septicemia. P-values $<0.05$ was statistically significant.

\section{Result}

A total of 450 neonates were admitted during the study period into the SCBU. Three hundred and sixty of these babies met the inclusion criteria and were recruited. Of these, 72 babies had neonatal sepsis confirmed by blood culture, hence neonatal sepsis accounted for $16 \%$ of all admissions into the SCBU. Forty-three $(59.7 \%)$ of these were in-born and the remaining $29(40.3 \%)$ were outborn.

The mean age of babies who had septicaemia was $78.1 \pm 147.5$ hours. The mean age of in-born babies with septicaemia was $38.1 \pm 98.8$ hours and this was not significantly lower than $105.0 \pm 168.7$ hours for out-born babies with septicaemia $(p=0.06)$.

Of the 72 babies with sepsis, $56(77.8 \%)$ had EOS as against $16(22.2 \%)$ who had LOS. The mean gestational age at delivery was $36.1 \pm 4.6$ weeks for the babies with EOS and $38.1 \pm 1.7$ weeks for babies with LOS ( $p=$ 0.09). Two in five babies with EOS were preterm compared with only one preterm baby presenting with LOS. The association between preterm birth and EOS was statistically sinificant. $(p=0.01)$.

The mean weight of the babies with EOS was $2.40 \pm 0.94$ $\mathrm{kg}$ and was significantly less than $3.11 \pm 0.67 \mathrm{~kg}$ for the babies with LOS $(p=0.01)$. Almost half of the babies with EOS were LBW compared with one in eight babies with LOS. Low birth-weight babies were significantly more likely to present with EOS ( $p=0.04)$.

Thirty-five $(62.5 \%)$ of 56 babies with EOS and two $(12.5 \%)$ of 16 babies with LOS had perinatal asphyxia. The higher percentage of babies with EOS compared to LOS who had perinatal asphyxia was statistically significant $(p=0.01)$. Half of the babies with LOS were delivered outside health facilities while $14.3 \%$ of babies with EOS were not delivered in health facilities. This was statistically significant $(p=0.01)$. Gender, social class, and prolonged rupture of membrane as shown in Table 1, did not significantly influence the risk of EOS or LOS among the population studied. 
Table 1: Comparison between risk factors for Early (EOS) and Late Onset Sepsis (LOS)

\begin{tabular}{|c|c|c|c|c|c|c|}
\hline Risk Factors & $\begin{array}{l}\text { Babies } \\
\text { with EOS }\end{array}$ & $\begin{array}{l}\text { Babies } \\
\text { with LOS }\end{array}$ & Crude OR ( $95 \% \mathrm{CI})$ & $\begin{array}{l}\text { P- } \\
\text { value }\end{array}$ & $\begin{array}{l}\text { Adjusted OR (95\% } \\
\mathrm{Cl})\end{array}$ & $\begin{array}{l}\mathrm{P} \text { - } \\
\text { value }\end{array}$ \\
\hline Birthweight $<2.5 \mathrm{~kg}$ & 25 & 1 & $12.10(1.49-97.97)$ & $<0.01$ & $53.17(1.2552 .13)$ & 0.04 \\
\hline EGA <37weeks & 22 & 1 & $9.71(1.20-98.79)$ & 0.01 & $1.41(0.04-26.55)$ & 0.86 \\
\hline Place of Delivery & 29 & 14 & $6.52(1.35-31.38)$ & 0.01 & $31.69(3.83-262.03)$ & $<0.01$ \\
\hline PROM & 15 & 5 & $1.24(0.37-4.17)$ & 0.73 & - & - \\
\hline Perinatal Asphyxia & 31 & 3 & $5.37(1.38-20.97)$ & 0.01 & $22.34(3.3-152.38)$ & $<0.01$ \\
\hline Male sex & 29 & 10 & $0.64(0.21-2.08)$ & 0.45 & - & - \\
\hline
\end{tabular}

The clinical features of the babies with EOS and LOS are shown in table 2. Hypothermia, pallor, poor activity, poor suckling and respiratory distress were more com- monly observed in EOS than LOS. However, only respiratory distress was more significantly observed in EOS $(p=0.01)$. Fever and irritability were more common in babies with LOS.

Table 2: Comparison between the clinical features of EOS and LOS

\begin{tabular}{|c|c|c|}
\hline Clinical Features & Babies with EOS & $\begin{array}{l}\text { Babies } \\
\text { with LOS }\end{array}$ \\
\hline Convulsion & 9 & 3 \\
\hline Diarrhea & 1 & 1 \\
\hline Vomiting & 1 & 1 \\
\hline Poor activity & 35 & 3 \\
\hline Irritability & 1 & 4 \\
\hline Fever & 9 & 8 \\
\hline Jaundice & 10 & 5 \\
\hline Pallor & 7 & 1 \\
\hline Hypothermia & 22 & 2 \\
\hline Sclerema & 1 & 0 \\
\hline Poor suck & 27 & 4 \\
\hline $\begin{array}{l}\text { Respiratory } \\
\text { distress }\end{array}$ & 33 & 2 \\
\hline
\end{tabular}

$\begin{array}{ll}\text { Odd's ratio (95\% CI) } & \begin{array}{l}\text { P- } \\ \text { value }\end{array} \\ 0.96(0.67-1.36) & 1.00 \\ 0.64(0.16-2.56) & 0.93 \\ 0.64(0.16-2.56) & 0.92 \\ 1.49(1.13-1.97) & <0.01 \\ 0.24(0.04-4.17) & <0.01 \\ 0.62(0.39-0.98) & 0.01 \\ 0.83(0.57-1.21) & 0.42 \\ 1.14(0.85-1.54) & 0.80 \\ 1.29(1.04-1.61) & 0.05 \\ 1.29(1.14-1.46) & 1.00 \\ 1.23(0.97-1.56) & 0.17 \\ 1.51(1.17-1.98) & <0.01\end{array}$

Table 3 shows no significant difference in the laboratory features between EOS and LOS in this study. However, the mean laboratory results as shown in Table 4 revealed that the mean platelet count and random blood sugar were lower among the neonates with EOS. 
Table 3: Comparison between laboratory features of Early (EOS) and Late onset sepsis (LOS)

\begin{tabular}{ll}
$\begin{array}{l}\text { Laboratory } \\
\text { features on } \\
\text { admission }\end{array}$ & $\begin{array}{l}\text { Babies with } \\
\text { No (\%) }\end{array}$ \\
$\begin{array}{l}\text { Anaemia } \\
\text { Hyperglycaemia }\end{array}$ & $11(19.6)$ \\
Hypoglycaemia & $2(3.6)$ \\
Leucocytosis & $9(16.1)$ \\
Metabolic Acidosis & $13(23.2)$ \\
Neutropenia & $27(48.2)$ \\
Neutrophilia & $10(17.9)$ \\
Thrombocytopenia & $7(12.5)$ \\
\multicolumn{2}{r}{ * Yate's correction applied }
\end{tabular}

Babies with LOS № (\%)

$4(25.0)$

2 (12.5)

$2(12.5)$

$7(43.8)$

$8(50.0)$

$1(6.25)$

$2(12.5)$

$11(68.8)$
P-value

$0.91^{*}$

$0.45^{*}$

$1.00^{*}$

0.11

0.90

$0.46^{*}$

$1.00 *$

0.84

Table 4: The Mean (SD) of laboratory features among the 72 babies with sepsis

\begin{tabular}{lllll}
\hline Laboratory feature & $\begin{array}{l}\text { EOS }(\mathbf{n}=\mathbf{5 6}) \\
\text { Mean (SD) }\end{array}$ & $\begin{array}{l}\text { LOS }(\mathbf{n}=\mathbf{1 6}) \\
\text { Mean (SD) }\end{array}$ & \multirow{2}{*}{$\boldsymbol{T}$} & \multicolumn{1}{c}{} \\
\hline Haematocrit (\%) & $48.8(8.8)$ & $42.6(9.3)$ & 2.47 & 0.02 \\
White blood cell count $(\times \mathbf{1 0} / \mathrm{L})$ & $9657.5(5605.1)$ & $10376.3(6092.6)$ & 0.44 & 0.66 \\
Platelet count $(\times \mathbf{1 0} / \mathrm{L})$ & $130325.0(34906.7)$ & $\begin{array}{l}156062.5 \\
(58049.9)\end{array}$ & 2.22 & 0.03 \\
& & $5.7(5.0)$ & 2.24 & 0.03 \\
\hline
\end{tabular}

Staphylococcus aureus was the predominant bacterial isolate in both early onset $(69.0 \%)$ and late onset $(76.5 \%)$ sepsis in this study. Gram positive isolates were the most common isolates in both early onset (77.2\%) and late onset $(83.3 \%)$ neonatal sepsis in this study.

The antibiotics with the highest sensitivities were Cip- rofloxacin $(86.7 \%)$, Cefuroxime $(82.7 \%)$, Ceftriaxone $(81.3 \%)$, the rest is as shown in Table 5.

Eighteen (18) of the 72 babies with confirmed neonatal sepsis died giving overall mortality rate of $25 \%$. All the eighteen deaths were recorded in babies with EOS, meaning that $32 \%$ of the babies with confirmed EOS died.

Table 5: Antibiotic sensitivity pattern of the bacterial isolates ORGANISMS

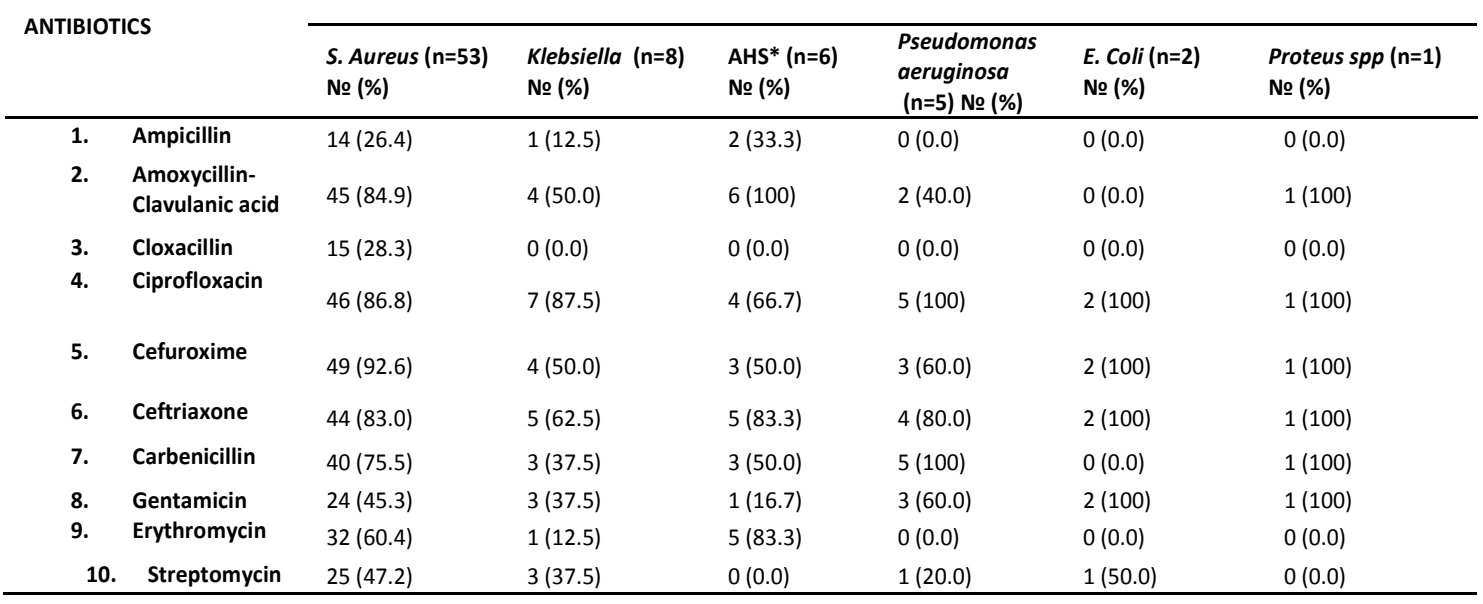

*AHS: Alpha Haemolytic Streptococcus 


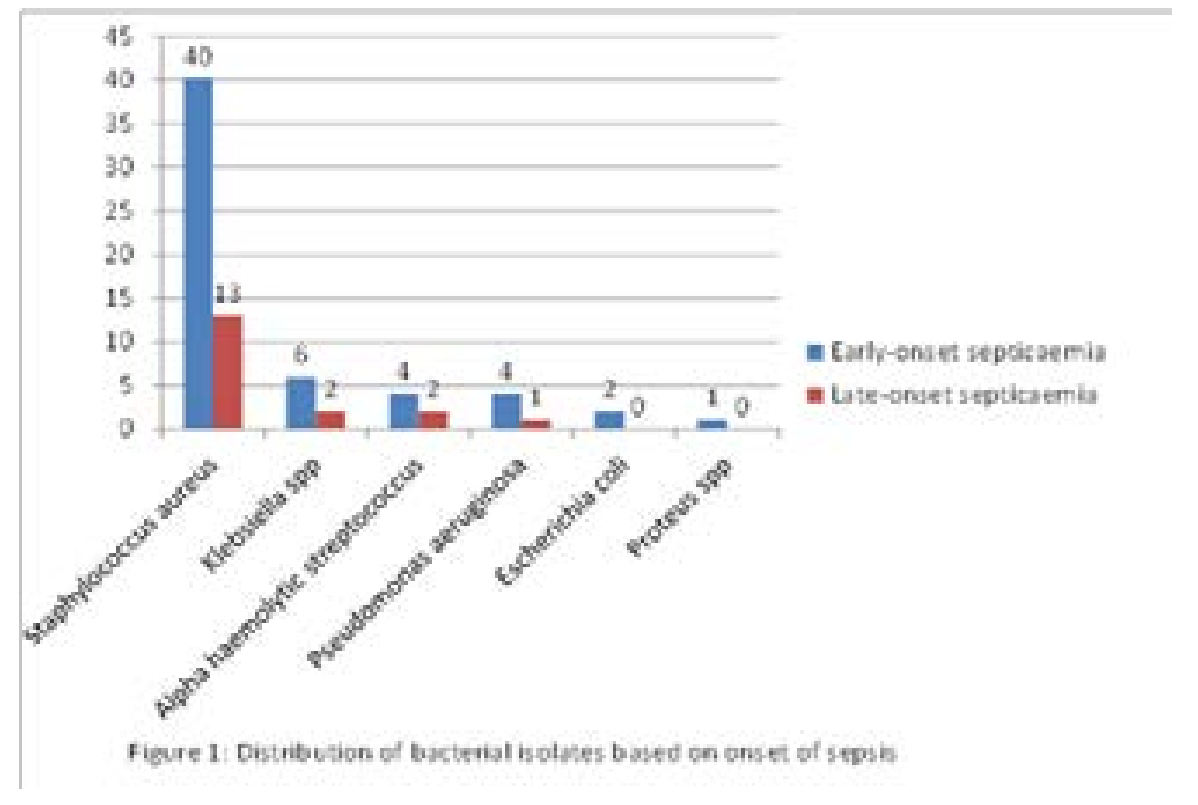

\section{Discussion}

The prevalence of neonatal sepsis from the study was $16 \%$ of all neonatal admissions into the SCBU. The study revealed that EOS was more common than LOS, however, Staphylococcus aureus was the most prevalent isolate in both groups. EOS was found to be more common among preterm, low birth weight babies and babies who suffered perinatal asphyxia. Out-born delivery was the identified risk factor for LOS in the study. Hypothermia, respiratory distress, poor suck and poor activity were the significant manifestations of EOS; fever and irritability were the symptoms significantly associated with LOS in this study. Low hematocrit, thrombocytopenia and hypoglycaemia were associated with EOS.

The neonatal sepsis prevalence rate of $16 \%$ observed from our study is similar to the reports of Ogunlesi et $\mathrm{al}^{17}$ from another hospital in South-West Nigeria, but less than $22 \%$ reported by Iregbu et $\mathrm{al}^{18}$ in Northern Nigeria and $23.9 \%$ reported by Ojukwu et $\mathrm{al}^{19}$ in South-Eastern Nigeria. This shows variation in prevalence across geographical locations within the country. This study reveals that EOS is more common than LOS and this finding is similar to findings from previous studies. ${ }^{10,20,21}$ This finding could probably be explained by the time of presentation in relation to the place of delivery especially since LOS was found commonly among out-born babies. The higher prevalence of LOS among out-born babies may be related to the non-availability of a Paediatrician or medical personnel at delivery and the non-specific symptoms of neonatal sepsis may have caused delay in presentation. Also, the kind of care received by these babies after delivery vis-à-vis cord care and poor feeding practices could account for the increased incidence of sepsis among this group of babies. ${ }^{22}$ Factors such as poor hygiene, poor cord care, bottle feeding and parenteral fluids as well as instrumentation have all been documented to increase the prevalence of community acquired LOS. ${ }^{23}$

Prematurity was found to be associated with EOS from our study; this is similar to findings from a study in Isra$\mathrm{el} ;{ }^{24}$ however it is at variance with the findings of West and Tabansi ${ }^{10}$ in South-East Nigeria which stated that prematurity was more associated with LOS probably because of prolonged hospital stay and increased risk of nosocomial infection. Prematurity is one of the leading causes of early neonatal admission, hence symptoms of sepsis are readily noted by the Paediatricians while the babies are on admission. Prematurity is usually associated with increased susceptibility to infections. ${ }^{1}$ This finding can also be explained by the time of sample collection in these babies; blood samples in this study were taken at the time of admission of the babies.

EOS was more common among babies who had perinatal asphyxia. This is similar to the findings of Bulkow$\operatorname{stein}^{24}$ in Israel. Asphyxia generally impairs the immune response of the neonate, ${ }^{1}$ this probably was responsible for the increased prevalence of EOS in the affected infants. The increased risk of EOS in babies with perinatal asphyxia may be a result of the need for vigorous resus- 
citation and multiple interventions in these babies. The aggressive resuscitation that usually follows asphyxia may aid the transmission of infection to the neonate.

Male gender was observed to be at higher risk for both EOS and LOS which is similar to the findings in Port Harcourt ${ }^{10}$ as well as the findings of Dawodu et $\mathrm{al}^{25}$ in Saudi Arabia. Female gender has been demonstrated to be protective in patients with sepsis, whereas male gender may be deleterious due to a diminished cell-mediated immune response and cardiovascular functions. ${ }^{26}$ Male sex hormones, i.e., androgens, have been found to suppress cell-mediated immune responses while female sex hormones have protective effects and this finding probably confer natural advantages on females in septic conditions. $^{26}$

The clinical features of neonatal sepsis are non-specific and vague. However, some symptoms are more likely to be found in EOS compared to LOS and vice versa. In this study, hypothermia, respiratory distress, poor activity and poor suck were more common among the babies with EOS which is similar to findings from West and Tabansi, ${ }^{10}$ Airede ${ }^{27}$ as well as Sankar et al. ${ }^{23}$ Hypothermia occurred more frequently in babies with EOS as against fever in babies with LOS in this study. This is probably due to the fact that most of the babies with EOS are LBW and preterm babies are likely to respond to infection with hypothermia. ${ }^{1}$ The observed hypothermia in EOS may also be due to the difficulty with temperature control usually exhibited by preterm and LBW babies. Though, fever, convulsion, irritability and jaundice were found to be more common in LOS, only fever and irritability were significantly associated with LOS.

Thrombocytopenia, neutropenia and hypoglycaemia were more commonly observed among the neonates with EOS when compared to those with LOS. Also, the mean haematocrit, mean platelet count and mean random blood sugar were all significantly lower among the babies with EOS compared with LOS. The findings of thrombocytopenia and neutropenia are similar to the result of Bulkowstein et al. ${ }^{23}$ Thrombocytopenia may be a presenting sign of neonatal sepsis and can last as long as 3 weeks; $10-60 \%$ of infants with sepsis have thrombocytopenia. ${ }^{28}$ Platelets are being speculated to play a role in the innate immune response to bacterial agents in the body by acting as sentinel cells that alert the innate immune system to the presence of bacterial agents in the body. ${ }^{29}$
Also, immune mediated thrombocytopenia has also been hypothesized. ${ }^{30}$ The neutropenia may be due to the fact that newborns are unable to mount adequate immune response in the first week of life as a result of immaturity of their immune system which puts preterm babies at a higher risk of sepsis. Hypoglycaemia can probably be explained by poor suckling and poor reserve which characterizes LBW and prematurity and these groups of babies had high prevalence of EOS in this study while the babies with LOS were mainly term babies who were older and probably were able to tolerate the stress of sepsis better. In addition, babies with LOS are also able to mount adequate or appropriate ketogenic response compared to babies who had EOS who are mostly LBW and preterm babies. $^{31}$

There was no difference in the bacterial isolates derived from babies with EOS and LOS. Staphylococcus aureus was predominant in both groups of neonates and this is similar to the findings of Fadero ${ }^{32}$ in Osogbo, Nathoo ${ }^{33}$ in Zimbabwe and Haque ${ }^{34}$ in Saudi Arabia. This however is different from what obtains in the developed countries where group B Streptococcus (GBS) is the most common isolate in EOS. ${ }^{1}$ These differences may be explained by environmental factors as women at term in developed countries in Europe and America show invasive GBS colonization rates of up to $30 \%$ thus posing a risk for GBS sepsis in their infants. This contrasts with the scenario in developing countries where the prevalence of GBS in pregnant women at term is low, and even when colonization occurs, it is usually with the non-invasive species. ${ }^{35,36}$ The bacterial isolates in this study were sensitive to Ciprofloxacin, Cefuroxime and Ceftriaxone in that order but showed significant resistance to commonly used antibiotics such as Ampicillin, Cloxacillin and Gentamicin. This finding is similar to what Kayange et $\mathrm{al}^{37}$ reported from Tanzania. This buttresses the need for continuous review of empirical antibiotics used in the treatment of NNS with a view to changing it as appropriate. Ojukwu et al ${ }^{19}$ from Abakaliki recommended the use of Ceftriaxone and Gentamicin as empirical therapy while awaiting blood culture result. The use of Ceftriaxone in the newborn has its attendant problem of worsening neonatal jaundice which may make it unsuitable as empirical antibiotic. Ciprofloxacin is also not recommended in the neonatal period because of its feared complication of arthropathy coupled with the recent publications by the European Medicines 
Agency on quinolones. ${ }^{38}$ Cefuroxime is recommended as the first line empirical antibiotic based on the results of this study. Given the high rate of in-vitro resistance to Ampicillin and Gentamicin which is the current empirical antibiotics ${ }^{14}$ there is a need for modification of practice. EOS usually manifest as a fulminant, multisystem infection with a high case fatality rate ${ }^{39}$ and this was reflected in the high mortality rate of $32.1 \%$ for EOS observed in this study compared to $100 \%$ survival in the neonates with LOS. The high mortality seen in the babies with EOS is much higher than $15.8 \%$ recorded by a Boma and Tabansi in Port Harcourt. ${ }^{10}$ The reason for this may also be due to the fact that other clinical conditions such as complications of prematurity contributed to the high mortality among this group of patients. A high index of suspicion is needed in the management of this category of babies and concerted efforts should be made to reduce delivery of preterm and low birth weight babies; pregnant women should also be encouraged to deliver at the appropriate facilities in order to ensure clean and safe delivery of their babies.

\section{Conclusion}

Early onset neonatal sepsis is associated with high likelihood of neonatal mortality. Unsupervised delivery, birth asphyxia and low birth weight are risk factors associated with neonatal sepsis. Efforts to ensure supervised hospital delivery and improvement in neonatal resuscitation may reduce the incidence of neonatal sepsis (both EOS and LOS) and its attendant complications.

\section{Abbreviations}

EOS - Early Onset sepsis; LOS - Late onset sepsis, SCBU - Special Care Baby Unit; WGH - Wesley Guild Hospital; OAUTHC - Obafemi Awolowo University Teaching Hospitals complex; SD - Standard deviation; EGA - Estimated Gestational Age; LBW - Low Birth weight; GBS - Group B streptococcus; NNS - Neonatal Sepsis

\section{Competing interests}

The authors declare that there are no conflicting interests.

\section{Funding}

The study was self funded.

\section{Authors' contributions}

OEO, ATA, OOA designed the study; OEO collected the data and wrote the first draft of the manuscript. OEO, AAA, ATA and OTA managed the literature searches. OTA analyzed the data and ALA managed the laboratory aspect of the study. OEO, AAA, ATA, OTA and OOA critically reviewed the manuscript. All authors read and approved the final manuscript.

\section{Acknowledgement}

The authors appreciate the parents/ caregivers and the babies who participated in this study. The resident doctors in the department of Paediatrics, the nursing staff of the SCBU and the staff of the microbiology laboratory unit of the hospital are appreciated.

\section{References}

1. Stoll BJ. Infections of the neonatal infant. In: Berhman RE, Kliegman RM, Jenson HB (editors). Nelson Textbook of Pediatrics, $17^{\text {th }}$ Edition. India, WB Saunders Company 2004: 623-39.

2. Misallati A, El-Bargathy S, Shembesh N. Blood culture proven neonatal septicaemia: a review of 36 cases. Eastern Mediterranean Health J 2000; 6: 483-6.

3. Black RE, Cousens S, Johnson HL, Lawn JE, Rudan I, Bassani DG et al. Global, regional, and national causes of child mortality in 2008: a systematic analysis. Lancet 2010; 375: 1969-87. Pubmed

4. Ibe BC. Neonatal infections. In: Azubuike JC, Nkanginieme KEO (editors). Paediatrics and Child Health in a Tropical Region, $2^{\text {nd }}$ Edition. Owerri, African Educational services 2007; 197-203.

5. Klinger G, Levy I, Sirota L, et al. Epidemiology and risk factors for early onset sepsis among very-low-birthweight infants. Am J Obstet Gynecol. 2009 Jul. 201(1): 38. E1-6.

6. Edwards MS, Baker CJ. Bacterial infections in the neonate. In: Long SS, Pickering LK, Prober CG (editors). Principles and Practice of Pediatric Infectious Disease. 4th ed. Philadephia: Elsevier Saunders; 2012. P. 538-44.

7. Yadav AK, Wilson CG, Prasad PL, Menon PK. Polymerase chain Reaction in Rapid Diagnosis of Neonatal Sepsis. Indian Pediatrics 2005; 42: 681-5. Pubmed

8. WHO Young infants Study Group. Bacterial etiology of serious infections in young infants in developing 
countries: results of a multicenter study. Pediatr Infect Dis J. 1999; 18 Suppl10: 17-22.

9. Shashikala ST, Kasturi AV, Shobha D, Krishna BVS. Clinic bacteriological study of neonatal septicemia in Hubli. Indian J Pediatr 2000; 67(3): 169-74.

10. West BA, Tabansi PN. Clinico-Bacteriological profile of early and late onset sepsis in a tertiary institution in Nigeria. J. Med. Med. Sci. 2012; 3(2): 107-11. Pubmed

11. Ogundare EO, Akintayo AA, Dedeke IOF, Okeniyi JA, Adeyemi LA, Ogunlesi TA et al. Neonatal Septicaemia in a Rural Nigerian Hospital: Aetiology, Presentation and Antibiotic sensitivity pattern. BJMMR 2016; 12(7): $1-7$.

12. Ako-Nai KA, Adejuyigbe EA, Ajayi FM, Onipede AO. The bacteriology of Neonatal septicaemia in Ile-Ife, Nigeria. J Trop Pediatr 1999; 45: 146-51.

13. Clinical and Laboratory Standards Institute: Performance standards for antimicrobial disk susceptibility tests. Approved standard. In Ninth edition Document M2- A9 Clinical and Laboratory Standards Institute, Wayne, PA; 2006.

14. Owa JA, Olusanya O. Neonatal bacteremia in Wesley Guild hospital, Ilesa, Nigeria. Ann Trop Paediatr. 1988; 8: 80-4.

15. Olusanya O, Okpere E, Ezimokhai M. The importance of Social Class in voluntary fertility control in a developing country. W Afr J Med. 1985; 4: 205-12.

16. SPSS for Windows. Release 13.0.0 SPSS Inc Standard Version 2004.

17. Ogunlesi TA, Ogunfowora OB, Osipenubi O, Olarewaju DM. Changing trends in newborn sepsis in Sagamu, Nigeria: Bacterial aetiology, risk factors and antibiotic susceptibility. J Paediatr Child Health. 2011; 47(1-2): 5-11. 18. Iregbu KC, Elegba OY, Babaniyi IB. Bacteriological profile of neonatal septicaemia in a tertiary hospital in Nigeria. African Health Sciences. 2006; 6: 151-4.

19. Ojukwu JU, Abonyi LE, Ugwu J, Orji JK. Neonatal septicaemia in high risk babies in Eastern Nigeria. J Perinatal Med. 2006; 34: 166-72.

20. Chako B, Sohi I. Early Onset Neonatal Sepsis. Indian J. Pediatr. 2005; 72: 23-26.

21. Rasul CH, Hassan MA, Habibullah M. Neonatal Sepsis and Use of Antibiotics in a Tertiary Care Hospital. Pak. J. Med. Sci. 2007; 23: 78-81.

22. Islam MN. Neonatal Infections in Developing Countries. Workshop on Improving Neonatal Survival in Developing Countries, Dharka. 2001; Pp 2-3.
23. Sankar MJ, Agarwal R, Deorari AK, Paul VK. Sepsis in the Newborn. Indian J Pediatr 2008; 75: 261-66.

24. Bulkowstein S, Ben-Shimol S, Givon-Lavi N, Melamed R, Shany E, Greenberg D. Comparison of early onset and community-acquired late onset sepsis in infants less than 3 months of age. BMC Pediatrics. 2016; 16: 82.

25. Dawodu A, Al Umran K, Twum-Danso KA. Case Control Study of Neonatal Sepsis: Experience from Saudi Arabia. J. Trop. Pediatr. 1997; 43: 84-8.

26. Angele MK, Pratschke S, Hubbard WJ, Chaudry IH. Gender differences in sepsis: cardiovascular and immunological aspects. Virulence. 2014; 5(1): 12-9.

27. Airede AI. Neonatal Septicaemia in an African City of High Altitude. J Trop Pediatr. 1992; 38: 189-91.

28. Khashu M, Osiovich H, Henry D. Persistent bacteremia and severe thrombocytopenia caused by coagulase-negative Staphylococcus in a neonatal intensive care unit. Pediatrics. 2006; 117(2): 340-8.

29. Eman M, El-Din RS, El-Sokkary MMA, Bassiouny MR, Hassan R. Epidemiology of Neonatal Sepsis and Implicated Pathogens: a study from Egypt. Biomed Research International. 2015; 2015: 1-12

30. Arif SH, Ahmad I, Ali SM,Khan HM. Thrombocytopenia and Bacterial Sepsis in Neonates. Ind J Haematol Bld Transfus. 2012; 28(3): 147-51.

31. Deshpande S, Bartlett K, Aynsley-Green A, WardPlatt MP. Persistent immaturity of counter regulatory ketogenesis in preterm infants. In: British Paediatric Association Annual Meeting. Warwick, British Paediatric Association 1994; 12.

32. Fadero FF, Aboderin AO, Onigbinde MO, Ako-Nai AK. Bacteria Pathogens and Antibiotics Sensitivity in Neonatal Septicaemia at the Ladoke Akintola University Teaching Hospital (LTH), Osogbo, Southwestern Nigeria. Int J Trop Med 2007; 2: 21-4.

33. Nathoo KJ, Mason PR, Chimbira THK. Neonatal septicaemia in Harare hospital. Central Afr J Med 1990; 36: 150-5.

34. Haque KN, Chagia AH, Shaheed MM. Half a decade of neonatal sepsis, Riyadh, Saudi Arabia. J Trop Paediatr 1990; 36: 20-3.

35. Biobaku OR, Olaleye AO, Adefusi OF, Adeyemi BA, Onipede AO, Loto OM, Imaralu JO.Group B streptococcus colonization and HIV in pregnancy: A cohort study in Nigeria. J Neonatal Perinatal Med. 2017; 10(1): 91-7.

36. Elikwu CJ, Oduyebo O, Ogunsola FT, Anorlu RI, Okoromah CN, König B. High group B streptococcus 
carriage rates in pregnant women in a tertiary institution in Nigeria. Pan Afr Med J. 2016; 25: 249.

37. Kayange N, Kamugisha E, Mwizamholya D, Jeremiah S, Mshana S. Predictors of positive blood culture and deaths among neonates with suspected neonatal sepsis in a tertiary hospital, Mwanza- Tanzania. BMC Pediatrics 2010, 10:39.
38. Disabling and potentially permanent side effects lead to suspension or restrictions of quinolone and fluoroquinolone antibiotics. EMA/795349/2018.

39. Polin RA, Parravicini E, Regan JA, Taeusch HW. Bacterial Sepsis and Meningitis. In: Taeusch HW, Ballard RA, Gleason CA, (editors). Avery's Diseases of the Newborn. $8^{\text {th }}$ ed. 2005: 551-57. 